\title{
The estimation of cardiac output by the Nexfin device is of poor reliability for tracking the effects of a fluid challenge
}

\author{
Xavier Monnet ${ }^{1 *}$, Fabien Picard ${ }^{1}$, Elsa Lidzborski ${ }^{1}$, Malcie Mesnil ${ }^{2}$, Jacques Duranteau ${ }^{2}$, Christian Richard ${ }^{1}$ and \\ Jean-Louis Teboul ${ }^{1}$
}

\begin{abstract}
Introduction: The Nexfin device estimates arterial pressure by the volume clamp method through a finger pneumatic cuff. It also allows to estimate cardiac index ( $\mathrm{Cl}_{\text {noninv }}$ ) by pulse contour analysis of the non-invasive arterial pressure curve. We evaluated the ability of the device to track changes in cardiac index induced by a fluid challenge.

Methods: We included 45 patients for whom a volume expansion (500 mL of saline infused over $30 \mathrm{~min}$ ) was planned. The volume expansion-induced changes in cardiac index measured by transpulmonary thermodilution ( $\mathrm{Cl}_{\text {inv, }}$ PiCCO device) and in $\mathrm{Cl}_{\text {noninv }}$ were recorded.

Results: In seven patients, the Nexfin could not record the arterial curve due to finger hypoperfusion. Considering both the values obtained before and after volume expansion ( $n=76$ pairs of measurements), the bias (lower and upper limits of agreement) between $\mathrm{Cl}_{\text {inv }}$ and $\mathrm{Cl}_{\text {noninv }}$ was $0.2(-1.8$ to 2.2$) \mathrm{L} / \mathrm{min} / \mathrm{m}^{2}$. The mean change in $\mathrm{Cl}_{\text {noninv }}$ was $10 \pm 11 \%$. The percentage error of $\mathrm{Cl}_{\text {noninv }}$ was $57 \%$. The correlation between the changes in $\mathrm{Cl}_{\text {inv }}$ and $\mathrm{Cl}_{\text {noninv }}$ observed during volume expansion was significant $(P=0.0002)$ with an $r^{2}=0.31$.

Conclusions: The estimation of $\mathrm{Cl}$ by the Nexfin device in critically ill patients is not reliable, neither for estimating absolute values of $\mathrm{Cl}$ nor for tracking its changes during volume expansion.
\end{abstract}

\section{Introduction}

Among the different devices that are available today for estimating cardiac output, the Nexfin technology (BMeye, Amsterdam, The Netherlands) is particularly original. This device provides a non-invasive estimation of cardiac output in two steps. First, this device allows a continuous estimation of the arterial pressure curve through the volume-clamp method [1]. For this purpose, the device includes an inflatable cuff that is wrapped around a finger. It also includes a photoplethysmographic device that measures the diameter of the finger arteries. At each systole, the photoplethysmographic device senses the increase of the finger arteries' diameter. A fast servocontrolled system immediately inflates the cuff in order

\footnotetext{
* Correspondence: xavier.monnet@bct.aphp.fr

${ }^{1}$ Service de réanimation médicale, Univ Paris-Sud, AP-HP, Hôpitaux

universitaires Paris-Sud, Hôpital de Bicêtre, 78, rue du Général Leclerc, 94270

Le Kremlin-Bicêtre, France

Full list of author information is available at the end of the article
}

to keep the arteries' diameter constant. Therefore, cuff pressure reflects the arterial pressure. Its continuous measurement allows estimation of the arterial pressure curve [2]. The second step is to estimate cardiac output from the non-invasive arterial pressure curve. For this purpose, the Nexfin device includes pulse contour analysis software that computes cardiac output from the arterial pressure curve [3].

The Nexfin has been quite largely validated for measuring arterial pressure [4-10]. However, its reliability to measure cardiac index $(\mathrm{CI})$ has been mainly investigated in non-critically ill patients [5,11-15]. Our aim was to assess whether the Nexfin estimation of CI was able to reflect $\mathrm{CI}$ in critically ill patients and to track its changes during a fluid challenge.

\section{() Biomed Central}

(c) 2012 Monnet et al.; licensee BioMed Central Ltd. This is an open access article distributed under the terms of the Creative Commons Attribution License (http://creativecommons.org/licenses/by/2.0), which permits unrestricted use, distribution, and reproduction in any medium, provided the original work is properly cited. 


\section{Materials and methods Patients}

This study took place in the medical and surgical intensive care units of a university hospital. It was approved by the institutional review board of our institution (Comité pour la Protection des Personnes Ile-de-France VII). Informed patient (or next-of-kin) consent was obtained from all patients. Patients were prospectively included if they presented an acute circulatory failure for which the attending physician had decided to administer fluid. This decision was based on inadequate tissue perfusion defined by the presence of at least one of the following signs [16-18]: (1) systolic blood pressure $<90 \mathrm{mmHg}$ (or a decrease $>50$ $\mathrm{mmHg}$ in previously hypertensive patients) or the need for norepinephrine, (2) urine output $<0.5 \mathrm{~mL} / \mathrm{kg} / \mathrm{hr}$ for at least $2 \mathrm{hrs}$, (3) tachycardia $>100$ beats/min, (4) skin mottling or (5) blood lactate $>2 \mathrm{mmol} / \mathrm{L}$.

\section{Hemodynamic measurements}

All patients had an internal jugular vein catheter and a thermistor-tipped arterial catheter (PV2024 Pulsion Medical Systems, Munich, Germany) in the femoral artery connected to the PiCCO2 device (Pulsion Medical Systems, Munich, Germany) to measure invasive cardiac index $\left(\mathrm{CI}_{\text {inv }}\right)$ and global end-diastolic volume (through transpulmonary thermodilution). The femoral arterial line was connected to the pressure sensor PV8115 (Pulsion Medical Systems, Munich, Germany) and the invasive arterial pressure was measured by the $\mathrm{PiCCO} 2$ device. In addition, all patients were monitored with a Nexfin device for measuring non-invasive arterial pressure and $\mathrm{CI}\left(\mathrm{CI}_{\text {noninv }}\right)$. An appropriate size finger cuff was applied around the middle phalanx of the third finger and connected to the device. A height sensor was fixed on one arm at the level of the heart for allowing the device to automatically correct for the hydrostatic pressure influences. If the arterial pressure signal was not obtained from the third finger, another finger was used until a signal could be obtained. If no signal could be obtained from any finger, efforts were made to rewarm the hand before all fingers were tested again.

The Nexfin device continuously records the arterial pressure curve and computes $\mathrm{CI}_{\text {noninv }}$ by pulse contour analysis. This analysis consists in estimating stroke volume by dividing the area under the systolic part of the arterial pressure curve by the aortic impedance [19]. Aortic impedance is determined from a three-element Windkessel model that incorporates the influence of nonlinear effects of arterial pressure and of patient's age, height, weight and gender on aortic mechanical properties [20]. The Nexfin method was developed on a database including invasive and non-invasive finger arterial pressures together with thermodilution cardiac output values obtained during cardiac surgery $[19,21]$, in healthy subjects during passive head-up tilt [22] and with low arterial pressure and treatment with catecholamines in severe septic shock [23].

\section{Study design}

At baseline, we measured arterial pressure, heart rate, $\mathrm{CI}_{\text {noninv }}$ and transpulmonary thermodilution variables including $\mathrm{CI}_{\mathrm{inv}}$ and global end-diastolic volume. Immediately after, volume expansion was performed by infusing $500 \mathrm{~mL}$ of saline over $30 \mathrm{~min}$. After volume expansion, we again recorded arterial pressure, heart rate, invasive and non-invasive arterial pressure, $\mathrm{CI}_{\text {noninv }}$ and transpulmonary thermodilution variables including $\mathrm{CI}_{\mathrm{inv}}$ and global end-diastolic volume. Patients in whom volume expansion increased CI by more than $15 \%$ were defined as 'volume responders' and the remaining ones as 'nonvolume responders' [16-18,24].

\section{Statistical analysis}

The normality of data distribution was tested with the Anderson-Darling test. Data are expressed as mean \pm standard deviation (SD) or median (interquartile range), as appropriate. $\mathrm{CI}_{\mathrm{inv}}$ was considered as the reference technique $[25,26]$. Values of invasive vs. non-invasive mean arterial pressure and of $\mathrm{CI}_{\text {inv }}$ vs. $\mathrm{CI}_{\text {noninv }}$ were compared by the Bland-Altman analysis. The percentage error was calculated as two times SD divided by the mean of the reference method [27]. Comparisons of hemodynamic variables between the different study times were assessed using a paired Student $t$ test or a Wilcoxon test, as appropriate. Comparisons between volume responders vs. non-volume responders were assessed using a two sample Student $t$ test or a Mann-Whitney $U$ test, as appropriate. We compared the relative changes of $\mathrm{CI}_{\text {inv }}$ to those of $\mathrm{CI}_{\text {noninv }}$ during volume expansion by linear regression analysis (for percent changes). For assessing the trending ability of $\mathrm{CI}_{\text {noninv, }}$, we constructed a four-quadrant plot, as described by Critchley et al. [28]. This allowed calculation of the percentage of total data points for which the directional changes of $\mathrm{CI}_{\text {noninv }}$ (increase or decrease) was concordant with those of $\mathrm{CI}_{\text {inv }}$. According to the least significant change of $\mathrm{CI}_{\mathrm{inv}}$ [29], we applied a 15\% exclusion zone. Correlations were assessed by the Pearson coefficient. A $P$ value $<0.05$ was considered statistically significant. The statistical analysis was performed with the MedCalc8.1.0.0 software (Mariakerke, Belgium).

\section{Results}

\section{Patients}

Forty-five patients were included in the study. Seven patients were excluded because the arterial curve was not obtainable from the Nexfin device, likely due to 
excessive vasoconstriction. All these seven patients exhibited clinical signs of severe skin hypoperfusion. In these patients, the mean arterial pressure was $43 \pm 7$ $\mathrm{mmHg}$, cardiac index before the fluid challenge was 2.9 $\pm 0.5 \mathrm{~L} / \mathrm{min} / \mathrm{m}^{2}$ and the dose of norepinephrine was 3.8 (2.1 to 6.7$) \mu \mathrm{g} / \mathrm{kg} / \mathrm{min}$. On average, the study was conducted 252 (20 to 6520) min after the beginning of the shock episode.

The characteristics of the 38 patients who could be analyzed are summarized in Table 1. Fifty-three percent of patients presented spontaneous breathing activity and $13 \%$ presented atrial fibrillation. Volume expansion significantly increased $\mathrm{CI}_{\text {inv }}$ by more than $15 \%(27 \pm 7 \%)$ in 16 volume responders (Table 2).

\section{Non-invasive estimation of mean arterial pressure}

Considering both the values obtained before and after volume expansion in all patients ( $\mathrm{n}=76$ pairs of measurements), the bias (lower and upper limits of agreement) between the invasive and non-invasive measurements of mean arterial pressure was 2 (-18 to 23$) \mathrm{mmHg}$ (Figure 1 ).

\section{Non-invasive estimation of cardiac index}

Considering both values obtained before and after volume expansion ( $\mathrm{n}=76$ pairs of measurements), the bias (lower

Table 1 Characteristics of patients.

\begin{tabular}{|c|c|}
\hline $\begin{array}{l}\text { Age } \\
\text { (mean } \pm S D \text {, years) }\end{array}$ & $65 \pm 15$ \\
\hline $\begin{array}{l}\text { Gender } \\
\text { (male/female, number of patients) }\end{array}$ & $20 / 18$ \\
\hline $\begin{array}{l}\text { SAPS } \| \\
(\text { mean } \pm \text { SD) }\end{array}$ & $55 \pm 15$ \\
\hline $\begin{array}{l}\text { Acute respiratory distress syndrome } \\
\text { (number of patients, \%) }\end{array}$ & $16(42 \%)$ \\
\hline $\begin{array}{l}\text { Atrial fibrillation } \\
\text { (number of patients, \%) }\end{array}$ & $5(13 \%)$ \\
\hline $\begin{array}{l}\text { Spontaneous breathing activity } \\
\text { (number of patients, \%) }\end{array}$ & $20(53 \%)$ \\
\hline $\begin{array}{l}\text { Tidal volume } \\
\text { (mean } \pm \mathrm{SD}, \mathrm{mL} / \mathrm{kg} \text { of predicted body weight) }\end{array}$ & $6.1 \pm 1.3$ \\
\hline $\begin{array}{l}\text { Patients receiving norepinephrine } \\
\text { (number of patients, \%) }\end{array}$ & 17 (45\%) \\
\hline $\begin{array}{l}\text { Body temperature } \\
\text { (mean } \pm \mathrm{SD},{ }^{\circ} \mathrm{C} \text { ) }\end{array}$ & $37.8 \pm 1.4$ \\
\hline $\begin{array}{l}\text { Type of shock } \\
\text { (number of patients, \%) }\end{array}$ & \\
\hline Septic & $33(87 \%)$ \\
\hline Hypovolemic & $5(13 \%)$ \\
\hline $\begin{array}{l}\text { Dose of norepinephrine } \\
\text { (median (interquartile range), } \mu \mathrm{g} / \mathrm{kg} / \mathrm{min} \text { ) }\end{array}$ & $0.4(0.21-0.60)$ \\
\hline
\end{tabular}

and upper limits of agreement) between $\mathrm{CI}_{\mathrm{inv}}$ and $\mathrm{CI}_{\text {noninv }}$ was $0.2(-1.8$ to 2.2$) \mathrm{L} / \mathrm{min} / \mathrm{m}^{2}$ (Figure 2). The percentage error of $\mathrm{CI}_{\text {noninv }}$ was $57 \%$. The correlation between the percent changes in $\mathrm{CI}_{\text {inv }}$ and $\mathrm{CI}_{\text {noninv }}$ observed during volume expansion was significant $(P=0.0002)$ with an $r^{2}$ $=0.31$ (Figure 3 ). The results of Bland-Altman analysis in patients without atrial fibrillation or norepinephrine administration are presented in Table 3.

The concordance rate between changes in $\mathrm{CI}_{\mathrm{inv}}$ and $\mathrm{CI}_{\text {noninv }}$ induced by volume expansion was $76 \%$ (Figure 3 ), meaning that in $76 \%$ of instances, $\mathrm{CI}_{\text {inv }}$ and $\mathrm{CI}_{\text {noninv }}$ changed in the same direction. When excluding changes lower than $15 \%$, the concordance rate was $84 \%$ (Figure 3).

An increase in $\mathrm{CI}_{\text {noninv }} \geq 15 \%$ allowed to detect volume responsiveness, that is, an increase in $\mathrm{CI}_{\mathrm{inv}} \geq 15 \%$, with a sensitivity of $43 \%$ (95\% confidence interval: 20 to $70 \%$ ), a specificity of $95 \%$ (77 to $100 \%$ ), a positive predictive value of $88 \%$ (44 to $100 \%$ ) and a negative predictive value of $70 \%$ (51 to $85 \%)$.

\section{Discussion}

The main finding of this study was that the non-invasive estimation of cardiac output provided by the Nexfin method was not reliable compared to transpulmonary thermodilution in critically ill patients even though, during volume expansion, $\mathrm{CI}_{\text {noninv }}$ and $\mathrm{CI}_{\text {noninv }}$ often changed in the same direction.

In the recent years, many efforts have been made to develop new techniques for monitoring cardiac output, with the particular aim of reducing their invasiveness. In this regard, the Nexfin technique seems particularly seductive since it only requires a finger pneumatic cuff. Nevertheless in the present study, we found that the Nexfin device was not reliable to estimate the absolute value of cardiac output. The Bland-Altman analysis showed a wide range for limits of agreement and the percentage error, which must be below $30 \%$ if transpulmonary thermodilution is used as the reference technique [27,29], was much higher. More than in a given value of cardiac output, clinicians might be more interested in cardiac output changes. In this regard also, the Nexfin estimation of cardiac output was not reliable. Indeed, the correlation between $\mathrm{CI}_{\text {noninv }}$ and $\mathrm{CI}_{\mathrm{inv}}$ was only weak. If analyzing this trending ability by a four-quadrant approach, as proposed by Critchley $e t$ al. [28], we found that the concordance rate was $84 \%$ when excluding from analysis changes in cardiac output that were too small to have any technological significance. It means that, in a majority of cases, $\mathrm{CI}_{\text {inv }}$ and $\mathrm{CI}_{\text {noninv }}$ changed in the same direction, which would suggest a good trending ability of $\mathrm{CI}_{\text {noninv. }}$. Nonetheless, this fourquadrant analysis only takes into account the direction of cardiac output changes and not their magnitude, that is, it only allows a rough evaluation. For clinical practice, not only the direction but also the amplitude of CI changes 
Table 2 Hemodynamic changes induced by volume expansion.

\begin{tabular}{|c|c|c|c|}
\hline & & Before volume expansion & After volume expansion \\
\hline Heart rate & volume responders $(n=16)$ & $104 \pm 33$ & $110 \pm 28$ \\
\hline (mean $\pm \mathrm{SD}$, beats $/ \mathrm{min}$ ) & non-volume responders $(n=22)$ & $98 \pm 20$ & $96 \pm 22$ \\
\hline Invasive mean arterial pressure & volume responders $(n=16)$ & $77 \pm 16$ & $80 \pm 20 \#$ \\
\hline (mean $\pm \mathrm{SD}$, mmHg) & non-volume responders $(n=22)$ & $74 \pm 14$ & $79 \pm 14$ \\
\hline Non-invasive mean arterial pressure & volume responders $(n=16)$ & $75 \pm 17$ & $80 \pm 18 \#$ \\
\hline (mean $\pm \mathrm{SD}$, mmHg) & non-volume responders $(n=22)$ & $70 \pm 16$ & $76 \pm 19 \#$ \\
\hline Invasive cardiac index & volume responders $(n=16)$ & $3.2 \pm 0.9$ & $3.9 \pm 1.0 \#$ \\
\hline$\left(\right.$ mean $\left.\pm \mathrm{SD}, \mathrm{L} / \mathrm{min} / \mathrm{m}^{2}\right)$ & non-volume responders $(n=22)$ & $3.8 \pm 9.0$ & $3.8 \pm 1.1$ \\
\hline Non-invasive cardiac index & volume responders $(n=16)$ & $3.2 \pm 1.2$ & $3.6 \pm 1.1 \#$ \\
\hline$\left(\right.$ mean $\left.\pm \mathrm{SD}, \mathrm{L} / \mathrm{min} / \mathrm{m}^{2}\right)$ & non-volume responders $(n=22)$ & $3.4 \pm 1.0$ & $3.6 \pm 1.0$ \\
\hline Global end-diastolic volume & volume responders $(n=16)$ & $726 \pm 112$ & $767 \pm 111 \#$ \\
\hline$\left(\right.$ mean $\left.\pm \mathrm{SD}, \mathrm{mL} / \mathrm{m}^{2}\right)$ & non-volume responders $(n=22)$ & $799 \pm 137$ & $814 \pm 156$ \\
\hline
\end{tabular}

$\# P<0.05$ vs. 'before volume expansion'.

might be important. For instance, the response to a fluid challenge is assessed by precisely measuring the relative change in $\mathrm{CI}$ that it induces. In this regard, we report a poor ability of $\mathrm{CI}_{\text {noninv }}$ to detect a positive response to fluid administration, in particular with a low sensitivity.

This poor reliability of the Nexfin device to estimate cardiac output is in discrepancy with some previous results obtained with the same technique [5,11-15,30]. A recent publication also reported a good ability of the Nexfin device to estimate cardiac output measured by transpulmonary thermodilution as well as its changes observed over time or during a passive leg-raising test [6]. The most plausible hypothesis explaining the discrepancy of such previous results with our findings is the difference in the population of interest. The studies that demonstrated a better reliability of the Nexfin were conducted in the operating theatre $[11,12]$, in cardiac surgery patients after

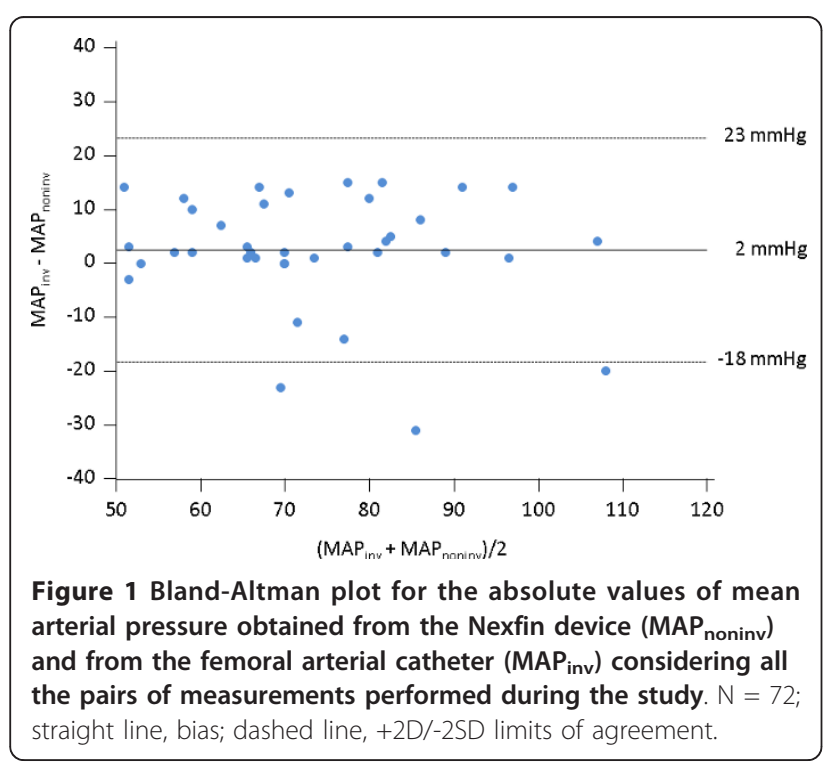

discontinuation of mechanical ventilation and inotropes [5], in patients undergoing resynchronization therapy [14], in an echocardiography laboratory [13] or in healthy subjects [15]. By contrast, in the present study, we included critically ill patients, a majority suffering from septic shock. Interestingly, our results are in agreement with another study reporting a poor reliability of the Nexfin and that was also conducted in intensive care unit patients [31]. In fact, such patients are much more likely to have an impaired finger perfusion, due either to endogenous sympathetic stimulation, to norepinephrine administration or to sepsis-related microcirculatory abnormalities. In this regard, the fact that the reliability of the Nexfin device was not different between patients with and without norepinephrine suggests that exogenous amines administered might not be the only factor explaining a poor finger perfusion in such critically ill patients. Poor finger perfusion

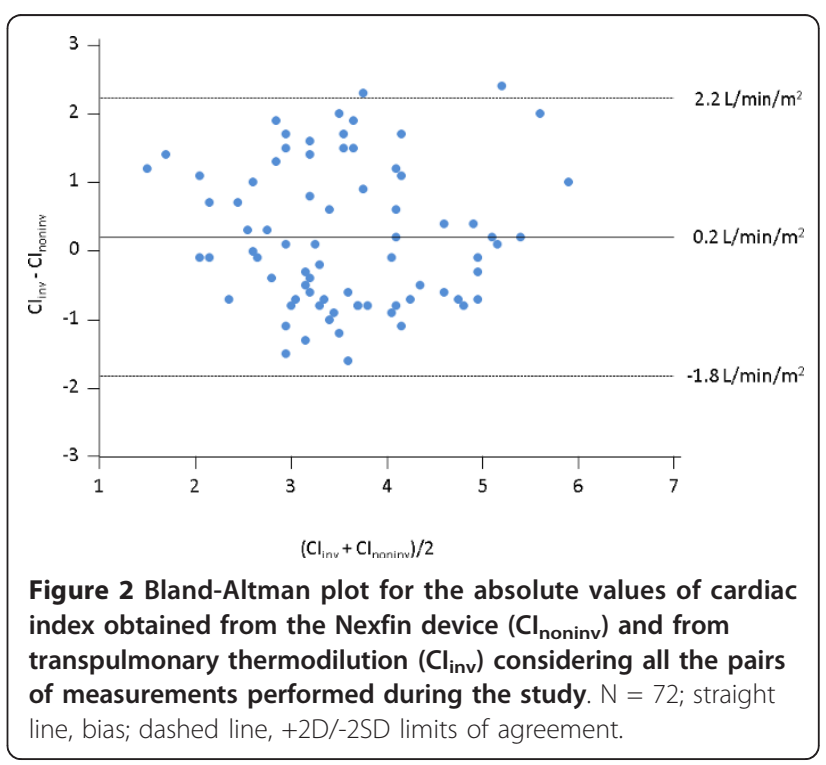




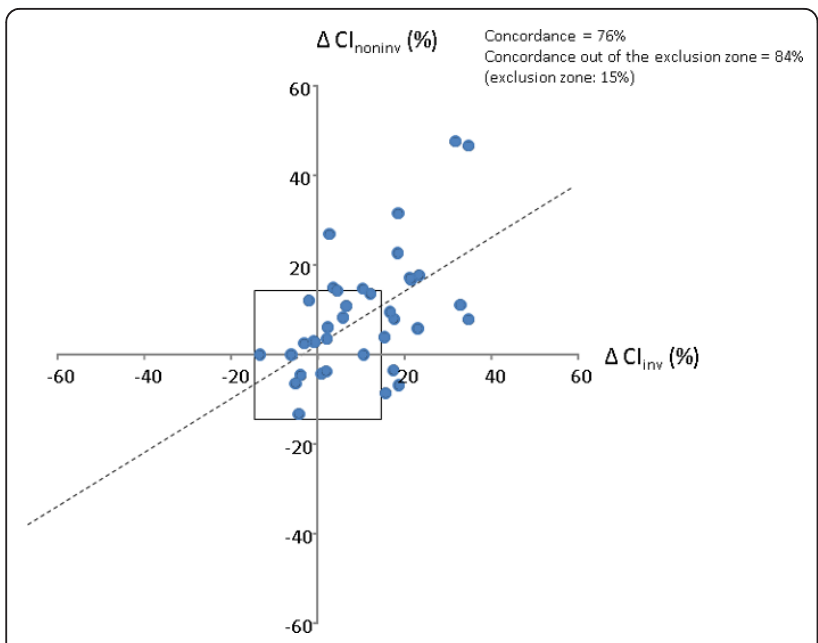

Figure 3 Trending ability of the cardiac index obtained from the Nexfin device $\left(\Delta \mathrm{Cl}_{\text {noninv }}\right)$ against cardiac index measured by transpulmonary thermodilution $\left(\Delta \mathrm{Cl}_{\text {inv }}\right)$ during volume expansion based on four-quadrant concordance analysis.

very likely impedes a correct assessment of the finger pressure curve by the volume-clamp method, which includes an analysis of the finger photoplethysmographic signal. In this regard, we observed that the non-invasive arterial pressure curve was not obtainable in a relatively large proportion of our patients. We made a similar observation with another volume-clamp device in a similar population [32]. This suggests that such a limitation is inherent to all these techniques of non-invasive arterial pressure assessment.

With the Nexfin device in the present study, we could not determine whether the poor reliability of estimation of cardiac output was related to a poor assessment of the arterial pressure curve or to a failure of the pulse contour analysis process since this proprietary process was unknown to us. Nevertheless, we hypothesize that the pulse contour analysis did not account a lot for the results. Indeed, the therapeutic intervention we used, that is, volume expansion, is known to alter the pulse contour analysis to a lesser extent than treatments modifying the properties of the arterial tree, such as vasoactive agents [33-35].

The estimation of arterial pressure by the Nexfin technique is based on the old volume-clamp method [1] but also includes an individual calibration technique (Physiocal) developed by Wesseling et al. [36]. Compared with the previous Finapress device, the Nexfin device has benefited from many technological improvements [7]. It has been reported to reliably estimate arterial pressure [4-10]. In the present study, the assessment of such reliability was based only on the comparison of mean arterial pressures provided by the Nexfin vs. the arterial line. Indeed, due to the pulse wave amplification phenomenon, the systolic and diastolic values of arterial pressure are physiologically different between the brachial pressure, estimated by the Nexfin device, and the femoral pressure that we invasively measured. By contrast, the mean arterial pressure is almost constant along the arterial tree and we used it for assessing the reliability of the Nexfin arterial pressure estimation. The bias between non-invasive and invasive mean arterial pressures was low, while the limits of agreement were relatively high. Previous studies reported better results for this device [4-10]. Like for the estimation of cardiac output, these different results might be explained by the fact that we included patients with septic shock receiving vasopressors, in whom the analysis of the non-invasive arterial pressure curve might be difficult due to a poor finger perfusion. The fact that the Nexfin device was of poorer reliability in critically ill patients than reported in the perioperative setting $[5,11,12]$ suggests that such a device is more suitable for the operating theatre than for intensive care units.

A first limitation of our study is that we could not investigate the ability of the Nexfin device to estimate pulse pressure variation, as we did for a similar device in a previous study [32]. This was due to the fact that we included a majority of patients in whom pulse pressure variation is of difficult measurement and interpretation, that is, spontaneous breathing activity and/or cardiac arrhythmias and/or acute respiratory distress syndrome $[37,38]$. Also, although the manufacturer recommends that the finger cuff should be applied to the middle phalanx of the second or third fingers, it was not the case in all the patients of the study since the position of the cuff was changed when the arterial pressure could not be obtained from the third finger. In addition, we cannot exclude that when the patient's hand was rewarmed, this could have distorted the Nexfin measurement by changing the microcirculation.

Table 3 Bland-Altman analysis for the comparison between cardiac index measured by the Nexfin device and transpulmonary thermodilution depending upon the absence of atrial fibrillation and norepinephrine infusion.

\begin{tabular}{cccc}
\hline Subgroup & $\begin{array}{c}\text { Bias } \\
\left(\mathrm{L} / \mathrm{min} / \mathrm{m}^{2}\right)\end{array}$ & $\begin{array}{c}\text { Upper limit of agreement } \\
\left(\mathrm{L} / \mathrm{min} / \mathrm{m}^{2}\right)\end{array}$ & $\begin{array}{c}\text { Lower limit of agreement } \\
\left(\mathrm{L} / \mathrm{min} / \mathrm{m}^{2}\right)\end{array}$ \\
\hline Whole population $(\mathrm{n}=38)$ & 0.2 & -1.8 & 2.2 \\
\hline Patients without atrial fibrillation $(\mathrm{n}=33)$ & 0.3 & -1.8 & 2.4 \\
\hline Patients without norepinephrine $(\mathrm{n}=21)$ & 0.3 & -1.8 & 2.3 \\
\hline
\end{tabular}


Finally, although we hypothesize that the discrepancy between the present study and previous publications was related to the type of included patients, we did not directly compare the device in similar conditions between critically ill and perioperative patients. Such a comparison remains to be performed.

\section{Conclusions}

The estimation of cardiac output by the Nexfin device in critically ill patients is not reliable, neither for estimating absolute values of cardiac output nor for tracking its changes during volume expansion.

\section{Key messages}

- The estimation of cardiac index by the volumeclamp method in critically ill patients was not reliable. - The method could not reliably track the changes in cardiac index induced by volume expansion.

- Due to finger hypoperfusion, the technique could not estimate cardiac index in a relatively large proportion of these patients with an acute circulatory failure.

\section{Abbreviations}

$\mathrm{Cl}_{\text {inv }}$ : cardiac index measured invasively by transpulmonary thermodilution; $\mathrm{Cl}_{\text {noninv: }}$ cardiac index measured non-invasively by the Nexfin device.

\section{Author details}

'Service de réanimation médicale, Univ Paris-Sud, AP-HP, Hôpitaux universitaires Paris-Sud, Hôpital de Bicêtre, 78, rue du Général Leclerc, 94270 Le Kremlin-Bicêtre, France. ${ }^{2}$ Service de réanimation chirurgicale, AP-HP, Hôpitaux universitaires Paris-Sud, Hôpital de Bicêtre, 78, rue du Général Leclerc, 94270 Le Kremlin-Bicêtre, France.

\section{Authors' contributions}

XM conceived the study, performed analysis and interpretation of the data and drafted the manuscript. FP performed the collection of data, contributed to analysis and interpretation of the data and to drafting of the manuscript. EL performed the collection of data, contributed to analysis and interpretation of the data and to drafting of the manuscript. MM performed the collection of data, contributed to analysis and interpretation of the data and to drafting of the manuscript. JD conceived the study, participated in its design, contributed to analysis and interpretation of the data and helped to draft the manuscript. CR participated in the design of the study, contributed to analysis and interpretation of the data and helped to draft the manuscript. J-LT conceived the study, participated in its design, contributed to analysis and interpretation of the data and helped to draft the manuscript. All authors read and approved the final manuscript.

\section{Competing interests}

Profs Jean-Louis Teboul and Xavier Monnet are members of the Medical Advisory Board of Pulsion Medical Systems. The other authors have no financial interest to disclose.

Received: 6 June 2012 Revised: 4 September 2012

Accepted: 23 October 2012 Published: 29 October 2012

\section{References}

1. Penaz J: Photoelectric measurement of blood pressure, volume and flow in the finger. Digest of the 10th International Conference on Medical and Biological Engineering Dresden; 1973.

2. Wesseling KH: Finapres, continuous noninvasive finger arterial pressure based on the method of Pĕnáz. In Blood Pressure Measurement. Edited by:
Meyer-Sabellek W, Anlauf M, Gotzen R, Steinfeld L. Darmstadt: Steinkopff Verlag; 1990:161-172.

3. Bogert LW, van Lieshout JJ: Non-invasive pulsatile arterial pressure and stroke volume changes from the human finger. Exp Physiol 2005, 90:437-446.

4. Hofhuizen CM, Lemson J, Hemelaar AE, Settels JJ, Schraa O, Singh SK, van der Hoeven JG, Scheffer GJ: Continuous non-invasive finger arterial pressure monitoring reflects intra-arterial pressure changes in children undergoing cardiac surgery. Br J Anaesth 2010, 105:493-500.

5. Bogert LW, Wesseling KH, Schraa O, Van Lieshout EJ, de Mol BA, van Goudoever J, Westerhof BE, van Lieshout JJ: Pulse contour cardiac output derived from non-invasive arterial pressure in cardiovascular disease. Anaesthesia 2010, 65:1119-1125.

6. Broch O, Bein B, Gruenewald M, Hocker J, Schottler J, Meybohm P, Steinfath $M$, Renner J: Accuracy of the pleth variability index to predict fluid responsiveness depends on the perfusion index. Acta Anaesthesiol Scand 2011, 55:686-693.

7. Eeftinck Schattenkerk DW, van Lieshout JJ, van den Meiracker AH, Wesseling KR, Blanc S, Wieling W, van Montfrans GA, Settels JJ, Wesseling KH, Westerhof BE: Nexfin noninvasive continuous blood pressure validated against Riva-Rocci/Korotkoff. Am J Hypertens 2009, 22:378-383.

8. Martina JR, Westerhof BE, van Goudoever J, de Beaumont EM, Truijen J, Kim YS, Immink RV, Jobsis DA, Hollmann MW, Lahpor JR, de Mol BA, van Lieshout JJ: Noninvasive continuous arterial blood pressure monitoring with Nexfin. Anesthesiology 2012, 116:1092-1103.

9. Nowak RM, Sen A, Garcia AJ, Wilkie H, Yang JJ, Nowak MR, Moyer ML: Noninvasive continuous or intermittent blood pressure and heart rate patient monitoring in the ED. Am J Emerg Med 2011, 29:782-789.

10. Maggi R, Viscardi V, Furukawa T, Brignole M: Non-invasive continuous blood pressure monitoring of tachycardic episodes during interventional electrophysiology. Europace 2010, 12:1616-1622.

11. Broch O, Renner J, Gruenewald M, Meybohm P, Schottler J, Caliebe A, Steinfath M, Malbrain M, Bein B: A comparison of the Nexfin(R) and transcardiopulmonary thermodilution to estimate cardiac output during coronary artery surgery. Anaesthesia 2012, 67:377-383.

12. Chen G, Meng L, Alexander B, Tran NP, Kain ZN, Cannesson M: Comparison of noninvasive cardiac output measurements using the Nexfin monitoring device and the esophageal Doppler. J Clin Anesth 2012, 24:275-283.

13. van der Spoel AG, Voogel AJ, Folkers A, Boer C, Bouwman RA: Comparison of noninvasive continuous arterial waveform analysis (Nexfin) with transthoracic Doppler echocardiography for monitoring of cardiac output. J Clin Anesth 2012, 24:304-309.

14. van Geldorp IE, Delhaas T, Hermans B, Vernooy K, Broers B, Klimusina t. Regoli F, Faletra FF, Moccetti T, Gerritse B, Cornelussen R, Settels JJ, Crijns HJ, Auricchio A, Prinzen FW: Comparison of a non-invasive arterial pulse contour technique and echo Doppler aorta velocity-time integral on stroke volume changes in optimization of cardiac resynchronization therapy. Europace 2011, 13:87-95.

15. Bartels SA, Stok WJ, Bezemer R, Boksem RJ, van Goudoever J, Cherpanath TG, van Lieshout JJ, Westerhof BE, Karemaker JM, Ince C: Noninvasive cardiac output monitoring during exercise testing: Nexfin pulse contour analysis compared to an inert gas rebreathing method and respired gas analysis. J Clin Monit Comput 2011, 25:315-321.

16. Monnet X, Osman D, Ridel C, Lamia B, Richard C, Teboul JL: Predicting volume responsiveness by using the end-expiratory occlusion in mechanically ventilated intensive care unit patients. Crit Care Med 2009, 37:951-956.

17. Monnet X, Rienzo M, Osman D, Anguel N, Richard C, Pinsky MR, Teboul JL: Esophageal Doppler monitoring predicts fluid responsiveness in critically ill ventilated patients. Intensive Care Med 2005, 31:1195-1201.

18. Monnet X, Rienzo M, Osman D, Anguel N, Richard C, Pinsky MR, Teboul JL: Passive leg raising predicts fluid responsiveness in the critically ill. Crit Care Med 2006, 34:1402-1407.

19. Wesseling KH, Jansen JR, Settels JJ, Schreuder JJ: Computation of aortic flow from pressure in humans using a nonlinear, three-element model. J Appl Physiol 1993, 74:2566-2573.

20. Westerhof N, Elzinga G, Sipkema P: An artificial arterial system for pumping hearts. J Appl Physiol 1971, 31:776-781.

21. Jansen JR, Schreuder JJ, Mulier JP, Smith NT, Settels JJ, Wesseling KH: A comparison of cardiac output derived from the arterial pressure wave 
against thermodilution in cardiac surgery patients. Br J Anaesth 2001, 87:212-222.

22. Harms MP, Wesseling KH, Pott F, Jenstrup M, Van Goudoever J, Secher NH Van Lieshout JJ: Continuous stroke volume monitoring by modelling flow from non-invasive measurement of arterial pressure in humans under orthostatic stress. Clin Sci (Lond) 1999, 97:291-301.

23. Jellema WT, Wesseling KH, Groeneveld AB, Stoutenbeek CP, Thijs LG, van Lieshout JJ: Continuous cardiac output in septic shock by simulating a model of the aortic input impedance: a comparison with bolus injection thermodilution. Anesthesiology 1999, 90:1317-1328.

24. Michard F, Boussat S, Chemla D, Anguel N, Mercat A, Lecarpentier Y, Richard C, Pinsky MR, Teboul JL: Relation between respiratory changes in arterial pulse pressure and fluid responsiveness in septic patients with acute circulatory failure. Am J Respir Crit Care Med 2000, 162:134-138.

25. Friesecke $S$, Heinrich A, Abel P, Felix SB: Comparison of pulmonary artery and aortic transpulmonary thermodilution for monitoring of cardiac output in patients with severe heart failure: validation of a novel method. Crit Care Med 2009, 37:119-123.

26. Sakka SG, Reinhart K, Meier-Hellmann A: Comparison of pulmonary artery and arterial thermodilution cardiac output in critically ill patients. Intensive Care Med 1999, 25:843-846.

27. Critchley LA, Critchley JA: A meta-analysis of studies using bias and precision statistics to compare cardiac output measurement techniques. J Clin Monit Comput 1999, 15:85-91.

28. Critchley LA, Lee A, Ho AM: A critical review of the ability of continuous cardiac output monitors to measure trends in cardiac output. Anesth Analg 2010, 111:1180-1192.

29. Monnet X, Persichini R, Ktari M, Jozwiak M, Richard C, Teboul JL: Precision of the transpulmonary thermodilution measurements. Crit Care 2011, 15 R204.

30. Stover JF, Stocker R, Lenherr R, Neff TA, Cottini SR, Zoller B, Bechir M: Noninvasive cardiac output and blood pressure monitoring cannot replace an invasive monitoring system in critically ill patients. BMC Anesthesiol 2009, 9:6

31. Fischer MO, Avram R, Carjaliu I, Massetti M, Gerard JL, Hanouz JL, Fellahi JL: Non-invasive continuous arterial pressure and cardiac index monitoring with Nexfin after cardiac surgery. Br J Anaesth 2012, 109:514-21.

32. Monnet $X$, Dres M, Ferre A, Le Teuff G, Jozwiak M, Bleibtreu A, Le Deley MC, Chemla D, Richard C, Teboul JL: Prediction of fluid responsiveness by a continuous non-invasive assessment of arterial pressure in critically ill patients: comparison with four other dynamic indices. Br J Anaesth 2012, 109:330-338.

33. Meng L, Phuong Tran N, Alexander BS, Laning K, Chen G, Kain ZN, Cannesson M: The impact of phenylephrine, ephedrine, and increased preload on third-generation Vigileo-FloTrac and esophageal Doppler cardiac output measurements. Anesth Analg 2011, 113:751-757.

34. Monnet X, Anguel N, Jozwiak M, Richard C, Teboul JL: The third-generation Flotrac/Vigileo does not reliably track the changes in cardiac output induced by norepinephrine in critically ill patients. Br J Anaesth 2012, 108:615-622

35. Monnet X, Anguel N, Naudin B, Jabot J, Richard C, Teboul JL: Arterial pressure-based cardiac output in septic patients: different accuracy of pulse contour and uncalibrated pressure waveform devices. Crit Care 2010, 14:R109.

36. Wesseling KH, Dewitt R, Weber AP: A simple device for the continuous measurement of cardiac output. Adv Cardiovasc Phys 1983, 5:1-52.

37. Monnet X, Bleibtreu A, Ferré A, Dres M, Gharbi R, Richard C, Teboul JL: Passive leg raising and end-expiratory occlusion tests perform better than pulse pressure variation in patients with low respiratory system compliance. Crit Care Med 2012, 40:152-157.

38. Marik PE, Monnet $X$, Teboul JL: Hemodynamic parameters to guide fluid therapy. Ann Intensive Care 2011, 1:1.

doi:10.1186/cc11846

Cite this article as: Monnet et al:: The estimation of cardiac output by the Nexfin device is of poor reliability for tracking the effects of a fluid challenge. Critical Care 2012 16:R212.

\section{Submit your next manuscript to BioMed Central and take full advantage of:}

- Convenient online submission

- Thorough peer review

- No space constraints or color figure charges

- Immediate publication on acceptance

- Inclusion in PubMed, CAS, Scopus and Google Scholar

- Research which is freely available for redistribution

Submit your manuscript at www.biomedcentral.com/submit 